Case Report

\title{
Minimally Invasive Approach of a Retrocaval Ureter
}

\author{
Nuno Fidalgo, ${ }^{1}$ Hugo Pinheiro, ${ }^{2}$ Frederico Ferronha, ${ }^{2}$ \\ Jorge Morales, ${ }^{2}$ and Luís Campos Pinheiro ${ }^{2}$ \\ ${ }^{1}$ Departamento de Urologia, Hospital das Forças Armadas, Azinhaga dos Ulmeiros, 1649-020 Lisboa, Portugal \\ ${ }^{2}$ Serviço de Urologia, Centro Hospitalar de Lisboa Central, EPE, Rua José António Serrano, 1150-199 Lisboa, Portugal \\ Correspondence should be addressed to Nuno Fidalgo; nunofid@gmail.com
}

Received 21 January 2016; Accepted 3 April 2016

Academic Editor: Giorgio Carmignani

Copyright (C) 2016 Nuno Fidalgo et al. This is an open access article distributed under the Creative Commons Attribution License, which permits unrestricted use, distribution, and reproduction in any medium, provided the original work is properly cited.

\begin{abstract}
The retrocaval ureter is a rare congenital entity, classically managed with open pyeloplasty techniques. The experience obtained with the laparoscopic approach of other more frequent causes of ureteropelvic junction (UPJ) obstruction has opened the method for the minimally invasive approach of the retrocaval ureter. In our paper, we describe a clinical case of a right retrocaval ureter managed successfully with laparoscopic dismembered pyeloplasty. The main standpoints of the procedure are described. Our results were similar to others published by other urologic centers, which demonstrates the safety and feasibility of the procedure for this condition.
\end{abstract}

\section{Introduction}

The retrocaval ureter is a rare congenital entity that causes external compression of the proximal ureter and usually becomes symptomatic in the third or fourth decade of life [1]. For the treatment of this condition, classical open pyeloplasty techniques had been the gold standard for many years. In 1994, Baba et al. were the first to report a successful laparoscopic pyeloplasty for a retrocaval ureter [2]. Over the time, other reports were presented with good results in less time. Current evidence supports the laparoscopic approach as fist-line treatment for this condition.

\section{Case Presentation}

We present the clinical case of a 35-year-old male with 12-month history of intermittent right flank pain. Physical examination and laboratorial investigation tests were unremarkable. Computed tomography (CT) scan after contrast infusion showed right hydroureteronephrosis, with the classical "reverse J" or "fishhook" deformity suggesting the presence of a retrocaval ureter (Figure 1) [3]. The mercaptoacetyltriglycine (MAG-III) renal scan showed right-side obstruction with a split function of $41.1 \%$ on the right kidney.
Therefore, the patient was proposed to undergo laparoscopic transperitoneal dismembered pyeloplasty.

The patient was placed in the left modified flank position at $45^{\circ}$, after induction of general anesthesia. We used a fourport approach with a $11 \mathrm{~mm}$ port to the right of the umbilicus, a $11 \mathrm{~mm}$ port half way between the first port and the right costal margin (in the midclavicular line), a $5 \mathrm{~mm}$ port in the midline (respecting the triangulation rule), and a $5 \mathrm{~mm}$ port in the right iliac fossa for suction device. The classic operative steps were performed for exposure: reflection of the ascending colon medially, identification of the ureter, and dissection of the right renal pelvis (Figure 2).

Careful dissection of the ureter was performed from the lateral border of the inferior vena cava (IVC) with the use of blunt dissection and bipolar device. Complete mobilization of the retrocaval portion of the ureter was achieved exposing its atretic and scarred portion (Figure 3). Then, we performed excision of the atretic and redundant portion and transposition of the ureter to an anterior position regarding the inferior vena cava. Previous to the reconstructive phase of the operation, we chose to suspend the renal pelvis to the anterior abdominal wall (passing a monofilament wire trough the renal pelvis and the abdominal wall with a straight needle), improving visualization and stabilization and dismissing the need for an "extra hand" (Figure 4). 


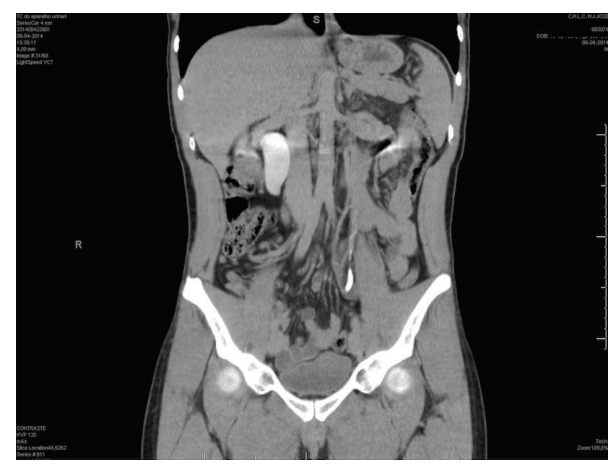

FIGURE 1: CT scan image showing the "reverse J" deformity.

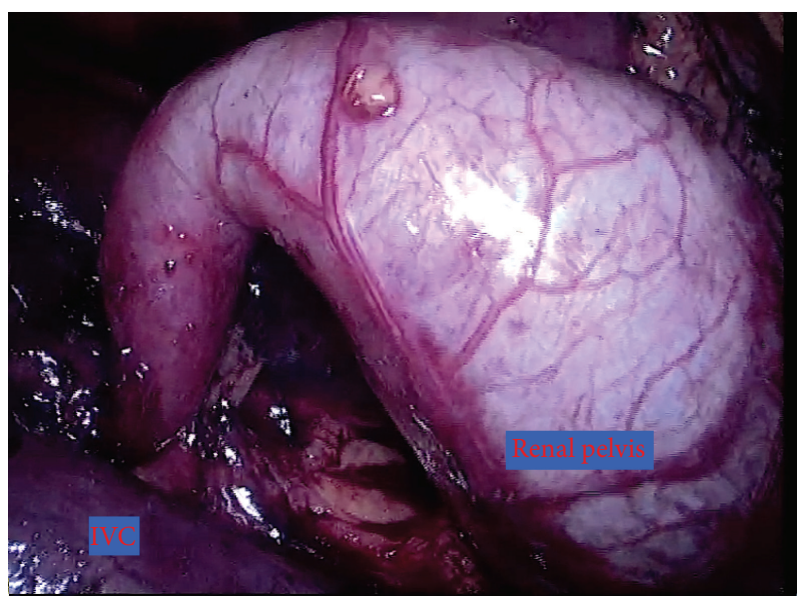

FIgURE 2: The renal pelvis after dissection.

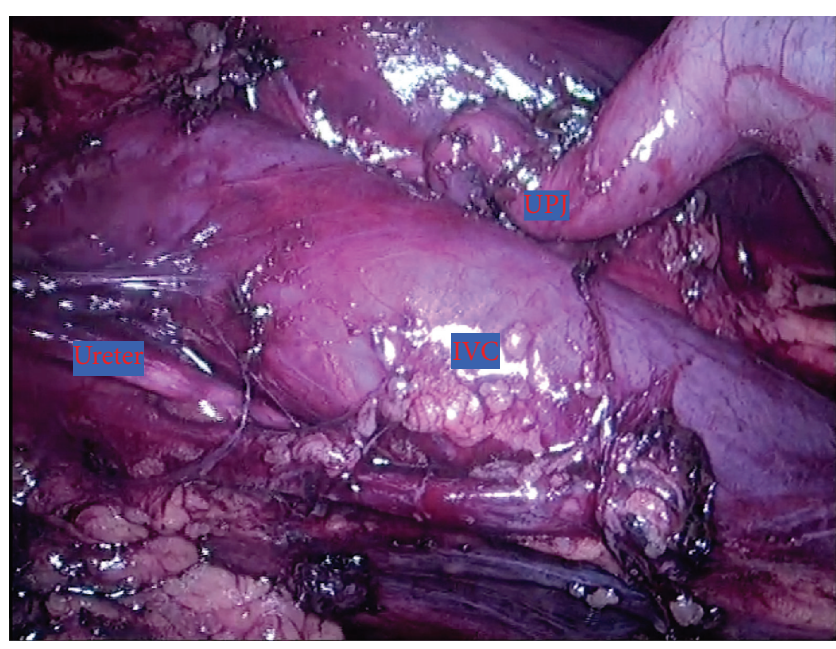

FIGURE 3: Renal pelvis, proximal ureter, and retrocaval portion dissected and mobilized.

Classical steps for pyeloplasty were then performed: spatulation of the ureter, introduction of a $6 \mathrm{Ch} 26 \mathrm{~cm}$ double-J stent in an antegrade fashion down the ureter into the bladder (passed along a 0.035 -inch glidewire). The anastomosis was performed using 3-0 polyglactin sutures in a continuous, tension-free fashion (Figure 5). Care was taken to place de

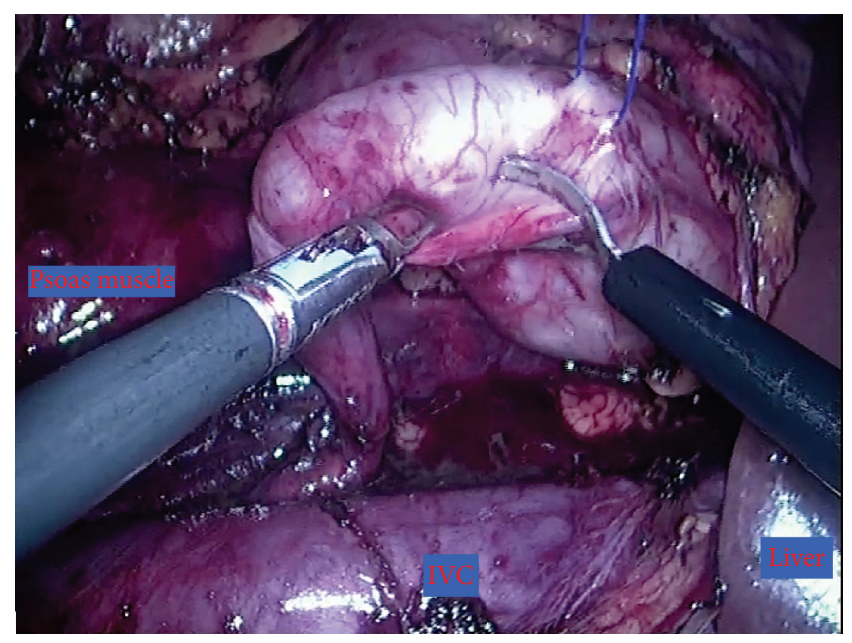

FIGURE 4: Preparing for pyeloplasty after suspension of the renal pelvis.

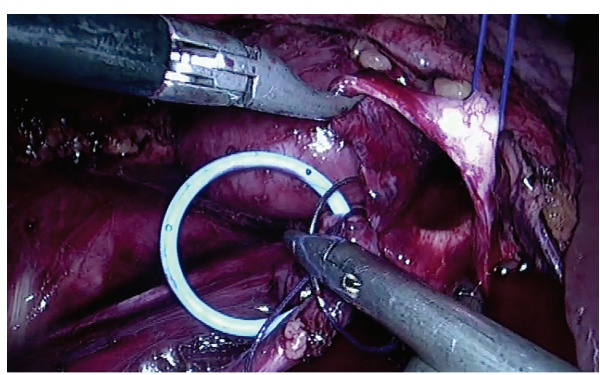

FIGURE 5: Starting the anastomosis, first on the posterior side with running suture.

proximal curl of the stent in the renal pelvis. The anastomosis was finally inspected confirming water tightness (Figure 6). A closed suction drain was placed. Blood loss was minimal and total operative time was 170 minutes.

The postoperative course was uneventful. Closed suction drain was removed at $48 \mathrm{~h}$. The patient was discharged at $72 \mathrm{~h}$. We removed the double-J stent after 6 weeks in the office. Pathology processing of the excised portion of the ureter revealed signs of chronic inflammation and fibrosis. At 3-month postoperative consult, the patient presented symptom-free and a MAG-3 scan was performed showing no signs of obstruction. A postoperative CT urography was also performed at 3 months and showed normal contrast drainage and no sign of complications.

\section{Discussion}

The retrocaval ureter is a rare congenital entity that causes external compression of the proximal ureter and usually becomes symptomatic in the third or fourth decade of life. Hoechstetter first described it in 1893 emphasizing the anatomical basis of this condition [15]. However, the developing of this clinical entity is due to a vascular malformation, making the designation preureteric vena cava more 


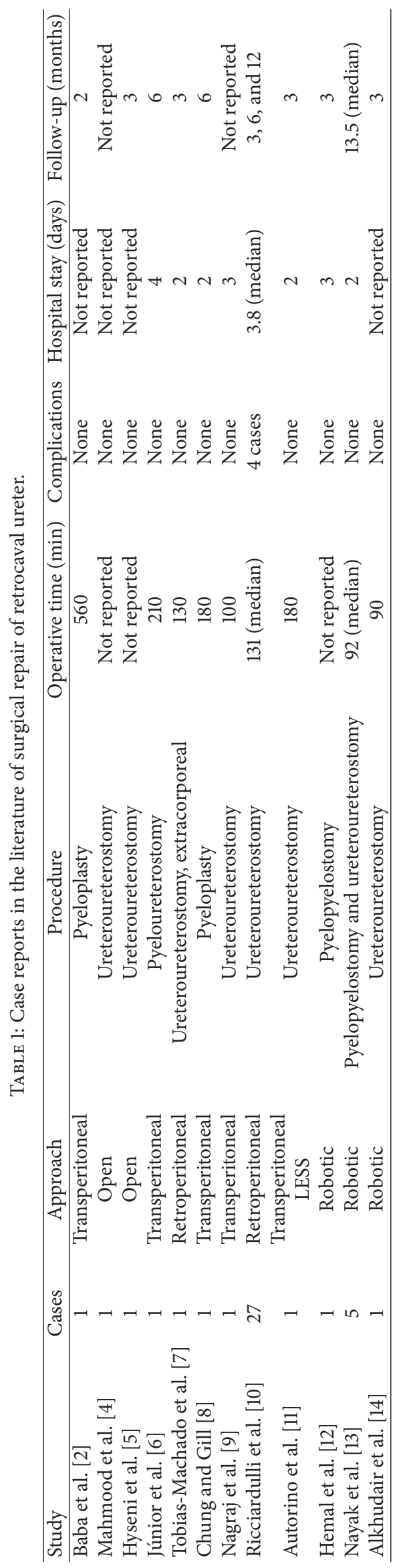




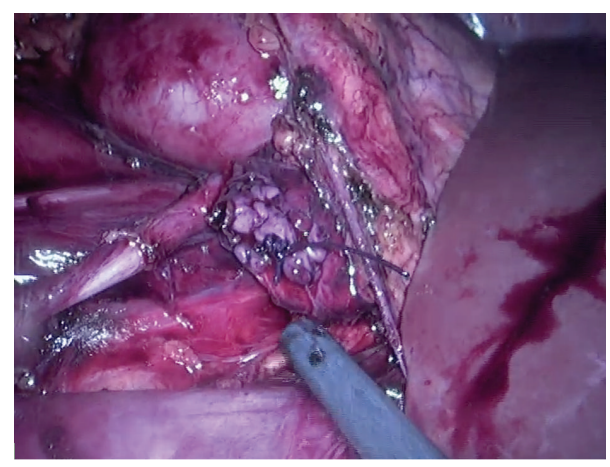

FIGURE 6: Final look of the anastomosis after inspection.

embryologically accurate. Several theories tried to explain this condition. The one described by Shulman in 1997, which states the persistence of the subcardinal vein as IVC, seems to be the most accepted one [16]. Others suggest the persistence of the posterior cardinal veins developing the IVC. Regardless of the theory, we find that the failure of the supracardinal vein to persist as IVC is a common point [17].

The surgical treatment of the retrocaval ureter is indicated in the evidence of signs or symptoms of obstruction [4, $5,18]$. For the treatment of this condition, classical open pyeloplasty techniques had been the gold standard for many years [19]. The first successful open dismembered pyeloplasty, published by Anderson and Hynes in 1949, was performed on a retrocaval ureter [20]. In 1994, Baba et al. were the first to report a successful laparoscopic pyeloplasty for a retrocaval ureter, with a total operative time of 560 minutes. With time, the experience and the lessons learned with other laparoscopic procedures, especially when involving intracorporeal suturing techniques, opened way for the standardization of the laparoscopic approach for retrocaval ureter all over the world [6]. In fact, we see reports of different laparoscopic approaches (transperitoneal, retroperitoneal, and laparoscopic assisted with extracorporeal anastomosis and laparoendoscopic single-site surgery (LESS)), reflecting the experience of each urologic center in the field of Laparoscopy in Urology, applied in retrocaval ureter surgery [7-11] (Table 1).

In our case we chose to perform pyeloplasty, instead of simple ureteroureterostomy, because of two reasons. First, the ureter looked very redundant, and to perform ureteroureterostomy it would also be necessary to excise a large portion of healthy ureter in order to give the ureter a more anatomical and functional aspect. The second reason regards the experience with successful laparoscopic pyeloplasty in our department. Pyeloplasty seemed easier to perform and less likely to develop stricture since we reconstruct a larger caliber structure. We could also expect better blood supply once the anastomosis is performed more apically. These all made strong points in the technical choice.

We found no need to additional placement of ureteral stent before the procedure, like in laparoscopic pyeloplasty for other causes of obstruction.
From the technical standpoint, we also remarked some aspects that we find essential for the safety and reproducibility of this minimal invasive procedure: suspension of the renal pelvis to the abdominal wall prior to the anastomosis is an easy and quick step which improves visualization and stabilization and dismisses the need for an extra port placement.

As in other fields of urologic surgery, robotic surgery of the retrocaval ureter was also reported in the literature. It seems that both robotic assisted repair and pure laparoscopic repair offer the same advantages for retrocaval ureter surgery, offering quick recovery and good cosmetic results. Apart from the ergonomic ease for the surgeon and easier intracorporeal suturing provided by robotics, current evidence favours both approaches at the same level, as far as results are concerned [12-14].

\section{Conclusions}

Laparoscopic dismembered pyeloplasty is the standard of care for the treatment of ureteropelvic junction obstruction. When facing a retrocaval ureter, additional challenges emerge. Despite these challenges, it is possible to maintain the advantages of minimal invasive treatment: quick convalescence and few complaints with excellent functional outcome.

\section{Competing Interests}

The authors declare that there are no competing interests.

\section{References}

[1] C. Vieira, M. Oliveira, C. Neto, R. Ramires, and P. Matos, "Veia cava inferior pré-ureteral: como uma formação vascular congénita pode ser causa de hidronefrose," Acta Pediátrica Portuguesa, vol. 40, no. 1, pp. 12-14, 2009.

[2] S. Baba, M. Oya, M. Miyahara, N. Deguchi, and H. Tazaki, "Laparoscopic surgical correction of circuivicaval ureter," Urology, vol. 44, no. 1, pp. 122-126, 1994.

[3] R. Hassan, A. Abd Aziz, and S. K. C. Mohamed, "Retrocaval ureter: the importance of intravenous urography," Malaysian Journal of Medical Sciences, vol. 18, no. 4, pp. 83-86, 2011.

[4] M. Mahmood, V. Tandon, U. S. Dwivedi, and P. B. Singh, "Retrocaval ureter: a rare entity in the spectrum of upper tract obstruction," JK-Practitioner, vol. 12, no. 1, pp. 24-25, 2005.

[5] N. Hyseni, S. Llullaku, M. Berisha et al., "Case presentation of preureteral vena cava and review of the literature," Open Journal of Urology, vol. 3, no. 5, pp. 206-209, 2013.

[6] O. A. Júnior, G. R. Bechara, R. R. Vieiralves, J. A. D. Júnior, H. G. Assunção, and T. A. De souza, "Laparoscopic treatment of obstrutive uropathy due to retrocaval ureter: literature review and case report," Brazilian Journal of Videoendoscopic Surgery, vol. 6, no. 4, pp. 179-185, 2013.

[7] M. Tobias-Machado, M. T. Lasmar, and E. R. Wroclawski, "Retroperitoneoscopic surgery with extracorporeal ureteroureteral anastomosis for treating retrocaval ureter," International Brazilian Journal of Urology, vol. 31, no. 2, pp. 147-150, 2005.

[8] B. I. Chung and I. S. Gill, "Laparoscopic dismembered pyeloplasty of a retrocaval ureter: case report and review of the literature," European Urology, vol. 54, no. 6, pp. 1433-1436, 2008. 
[9] H. K. Nagraj, T. A. Kishore, and S. Nagalakshmi, “Transperitoneal laparoscopic approach for retrocaval ureter," Journal of Minimal Access Surgery, vol. 2, no. 2, pp. 81-82, 2006.

[10] S. Ricciardulli, Q. Ding, X. Zhang, H. Li, M. Spagni et al., "Retroperitoneal laparoscopic approach for retrocaval ureter: our experience on 27 cases," Journal of Urology and Research, vol. 2, no. 4, p. 1033, 2015.

[11] R. Autorino, R. Khanna, M. A. White et al., "Laparoendoscopic single-site repair of retrocaval ureter: first case report," Urology, vol. 76, no. 6, pp. 1501-1505, 2010.

[12] A. K. Hemal, R. Rao, S. Sharma, and R. G. E. Clement, "Pure robotic retrocaval ureter repair," The International Brazilian Journal of Urology, vol. 34, no. 6, pp. 734-738, 2008.

[13] B. Nayak, P. N. Dogra, and N. P. Gupta, "Robotic repair of retrocaval ureter: a case series," African Journal of Urology, vol. 18, no. 3, pp. 135-137, 2012.

[14] W. K. Alkhudair, R. Seyam, H. M. Al Zahrani, M. F. Al Otaibi, and W. Al Taweel, "Robotic uretero-ureterostomy of the retrocaval ureter without excision of the retrocaval segment," Canadian Urological Association Journal, vol. 6, no. 2, pp. E38E41, 2012.

[15] P. Gupta, M. Khullar, R. Sharma, and R. Singh, "A rare presentation of the double inferior vena cava with an anomalous retrocaval right ureter: embryogenesis and clinical implications," Journal of Clinical and Diagnostic Research, vol. 7, no. 3, pp. 518-521, 2013.

[16] C. C. Schulman, “The ureter," in Pediatric Urology, B. O’Donnell and S. A. Koff, Eds., pp. 409-410, Butterworth-Heinemann, Oxford, UK, 3rd edition, 1997.

[17] P. C. Walsh et al., Campbell's Urology, W. B. Saunders, Philadelphia, Pa, USA, 10th edition, 2012.

[18] H. Hashim and C. R. J. Woodhouse, "Ureteropelvic junction obstruction," European Urology, Supplements, vol. 11, no. 2, pp. 25-32, 2012.

[19] A. Salonia, C. Maccagnano, A. Lesma et al., "Diagnosis and treatment of the circumcaval ureter," European Urology Supplements, vol. 5, no. 5, pp. 449-462, 2006.

[20] J. C. Anderson and W. Hynes, "RETROCAVAL URETER: a case diagnosed pre-operatively and treated successfully by a plastic operation," British Journal of Urology, vol. 21, no. 3, pp. 209-214, 1949. 


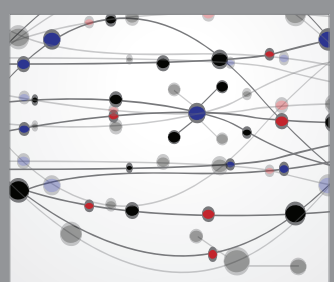

The Scientific World Journal
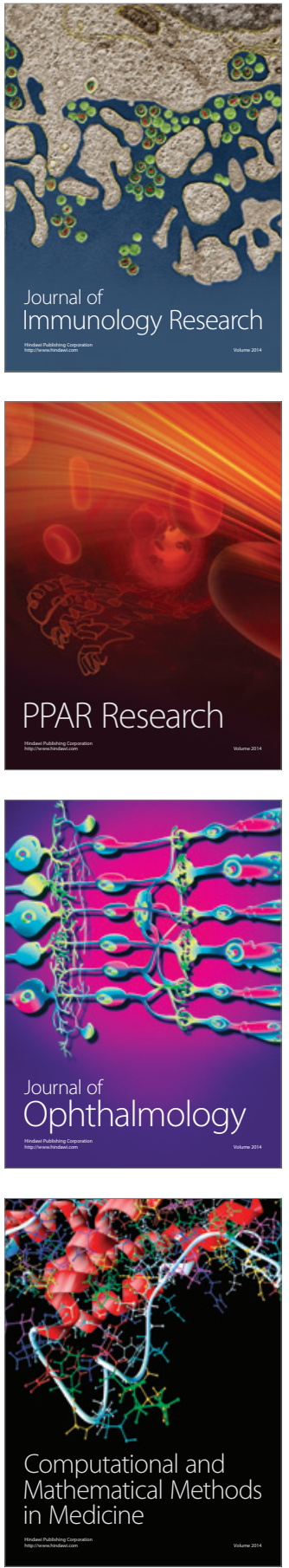

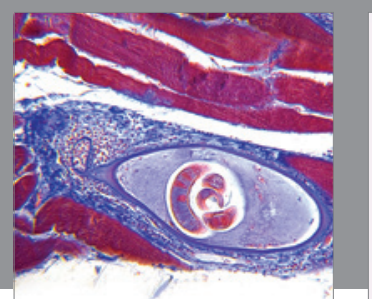

Gastroenterology Research and Practice

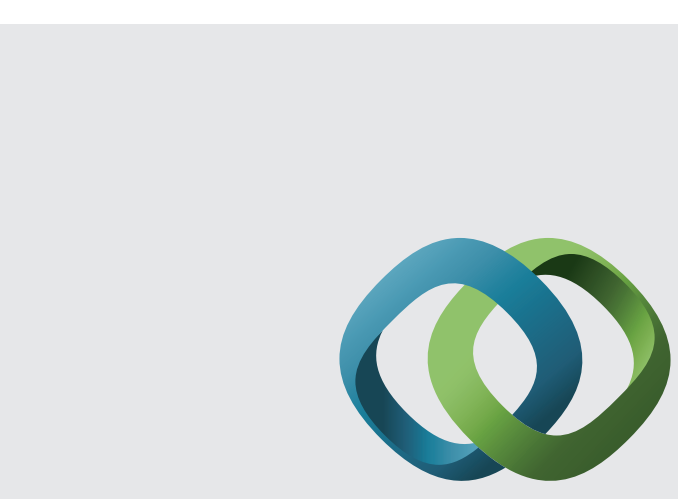

\section{Hindawi}

Submit your manuscripts at

http://www.hindawi.com
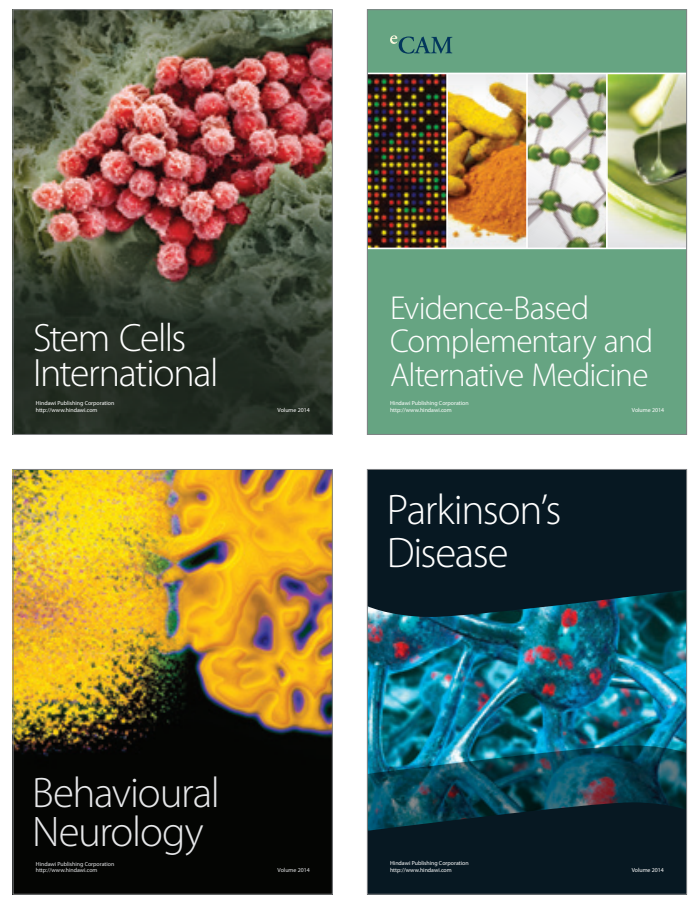
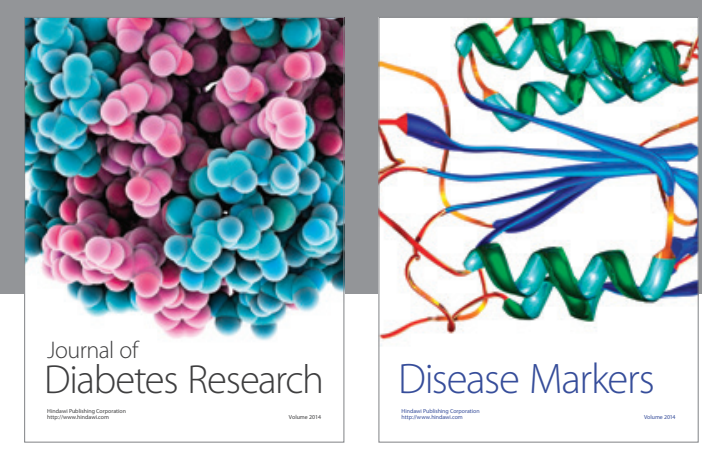

Disease Markers
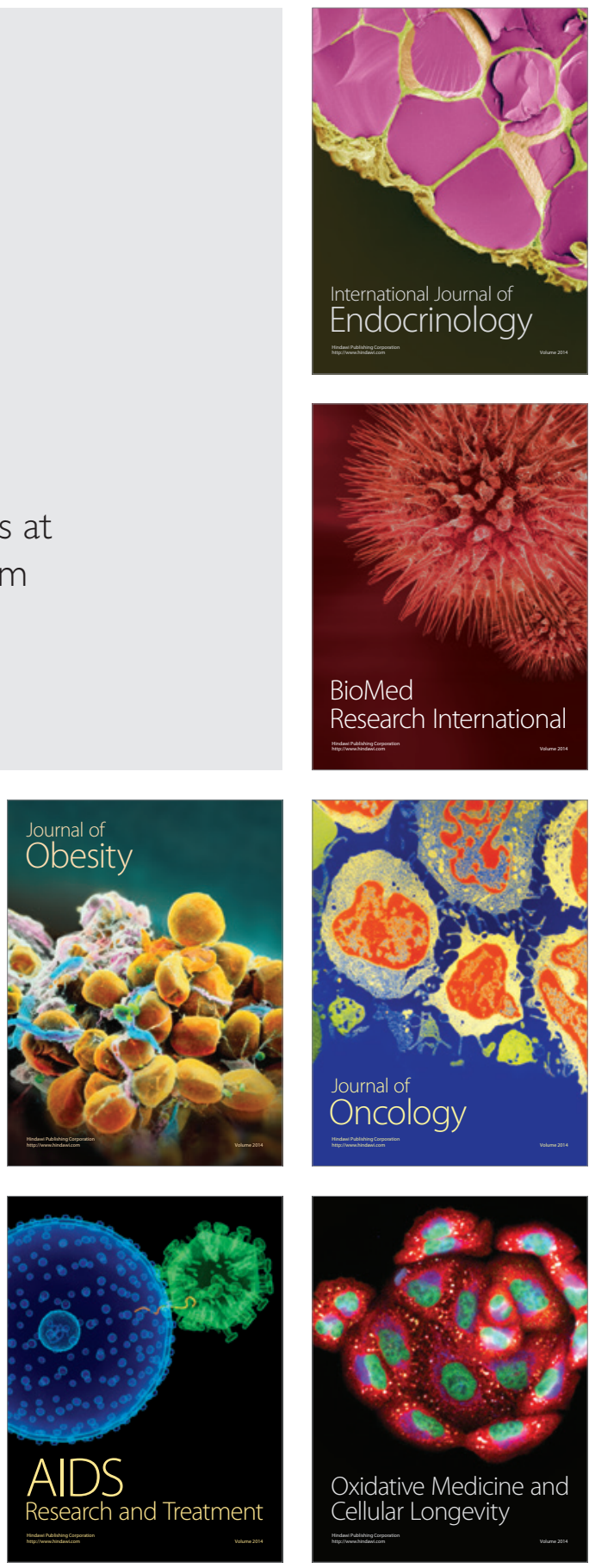